\title{
Natural Language Processing for Teaching Ancient Languages ${ }^{* 1}$
}

\section{Natural languages}

The notion of natural language refers to the challenge of analysing human communication. We hope to gain insight into our everyday interactions ${ }^{2}$ by examining our communicative behaviour. For this task, languages like English, Farsi or Ancient Greek are presumably more informative than programming languages like $\mathrm{C}$ or Python, because the latter rarely serve a strictly communicative purpose, but are rather used to process data for a specific workflow. To achieve that goal, machines usually rely on their own computational capacity, consulting external resources only if explicitly asked to do so. Humans, on the other hand, tend to use joint reasoning to solve advanced problems. ${ }^{3}$

When we decide to use human language as a research object, we may encounter a few problems that are not present in constructed languages: human languages evolve continuously ${ }^{4}$ and involve a great deal of ambiguity and interpretation. ${ }^{5}$ For humans, such evolution and vagueness is desirable to retain a sufficient amount of flexibility, which is needed in dynamic environments where social interaction is neither rigid nor perfectly consistent.

For machines, however, this constant interpretative performance of humans has to be emulated artificially. ${ }^{6}$ Depending on our end goal, we often need several steps to decode the meaning of, for example, an ancient text (see Fig. 1). Each of those steps plays an important role in providing the necessary information for a machine to decode a given linguistic input.

\footnotetext{
* The video of the talk, presented at the online conference Teaching Classics in the Digital Age on June 15-16, 2020, is available at https://doi.org/10.5446/51973.

1 This work is part of a project funded by the German Research Foundation (project number 316618374) and led by Malte Dreyer, Stefan Kipf, and Anke Lüdeling.

2 Crocker 2013, 482.

3 Textor 2011, 44

4 Ljunglöf et al. 2010, 60.

5 Palmer 2010, 15.

6 Ljunglöf et al. 2010, 59; Palmer 2010,9.

> This book chapter is published under the Creative Commons Attribution Attribution-ShareAlike 4.0 International license (https://creativecommons.org/licenses/by-sa/4.0/deed.en). Please note that individual, appropriately marked parts of the book chapter may be excluded from the license mentioned or may be subject to other copyright conditions. If such third party material is not under the Creative Commons license, any copying, editing or public reproduction is only permitted with the prior consent of the respective copyright owner or on the basis of relevant legal authorization regulations.
} 


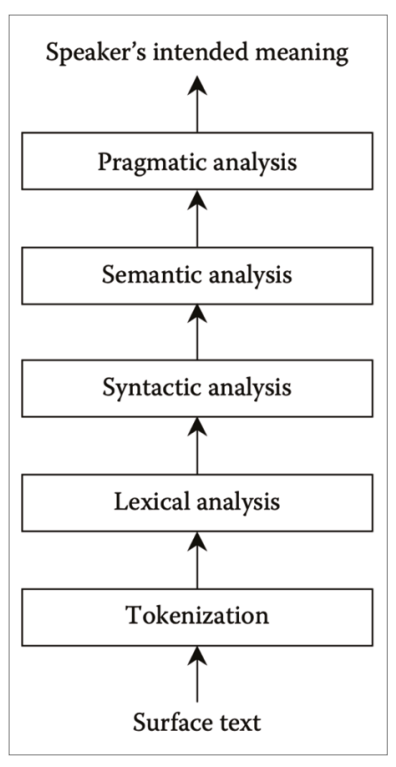

Fig. 1: Stages of natural language processing according to Dale 2010, p. 4.

Current systems for natural language processing (hereafter: NLP) are quite proficient in analysing various lexical aspects of texts in most languages. Syntax, on the other hand, is much harder to analyse, especially for languages where the availability of high-quality research data is quite limited. ${ }^{7}$ Unfortunately, this is true for the languages of most ancient cultures. Even for Latin, where a rich tradition survived, the majority of written evidence remains irrecoverably lost. Therefore, NLP applications for such problematic languages currently cover only a limited amount of syntactic or semantic analysis, let alone pragmatics. In the following, we shall look at several examples of what works with such applications, and what does not.

\section{Finding the right text}

Vocabulary is a crucial aspect of teaching ancient languages, which is why there have been ongoing efforts to determine a certain number of words that constitute a core vocabulary. ${ }^{8}$ Traditionally, it was assumed that such a basic vocabulary should be acquired in the initial learning phase, and then followed by a phase of extensive reading of ancient literature. ${ }^{9}$ Nowadays, however, longer learning processes are more strongly

7 McGillivray 2013, 3; Ragni et al. 2014; Karakanta et al. 2018, 168.

8 Utz 2000, 146; Jones et al. 2006; Robillard et al. 2014, 2.

9 Freie und Hansestadt Hamburg 2004, 10. 
emphasized, even for historical languages that we only learn at schools or universities. ${ }^{10}$ What we actually need to do is to measure the lexical knowledge for a given learner at any point time, which has been notoriously difficult for humans and machines alike. ${ }^{11}$

Once we know more about a learner's current lexical proficiency, another challenge awaits us: what is a suitable text passage or exercise for that person in order to further advance along the path of language learning? Basic operationalisations for this task include comparing a list of supposedly known words to a list of lemmata that occur in a text. Similar to computational models, ${ }^{12}$ learners will often struggle to deal with lemmata that go beyond their available vocabulary. Teachers therefore usually want to provide additional help, for example in the form of explanatory contexts, glosses, dictionaries, or simple translations. Unfortunately, such supportive measures may not prove consistently effective, because we often do not know the actual degree of (un-) familiarity for a given lexeme and learner. Since vocabulary knowledge is multidimensional, ${ }^{13}$ computational operationalisations of lexical progression need to incorporate more than just the binary decision of 'known/unknown'. This also applies to diagnosis and feedback, where the simple dichotomy 'correct/incorrect' is often insufficient to provide accurate information. What NLP (and research on vocabulary acquisition in general) needs is a consistent model for providing information on various error types, forms of knowledge, and understanding of tasks or instructions. ${ }^{14} \mathrm{~A}$ basic starting point in working towards this goal is to apply an extensive metadata schema to exercises, which separately encodes the types of interaction, linguistic phenomena and possible embedding in a larger progression.

Assuming we could successfully identify certain words to be learned, and found text passages in which these words occur, the next step would be to create appropriate exercises for this material. Traditionally, vocabulary has been acquired by memorizing lists of word equations in the form 'Latin word $=\mathrm{L} 1$ word' ${ }^{15}$ More recent approaches, on the other hand, have emphasized vocabulary acquisition in context, rather than as isolated word forms. ${ }^{16}$ Ideally, such contexts should contain authentic rather than artificial utterances $^{17}$ to avoid an oversimplification of language that would lead to a shock for learners later on when they are suddenly confronted with real-world texts. ${ }^{18}$ In this regard, NLP can be employed to make use of authentic text corpora to create contextualized vocabulary exercises. At the very least, this requires pairs of words, e. g. nouns and their

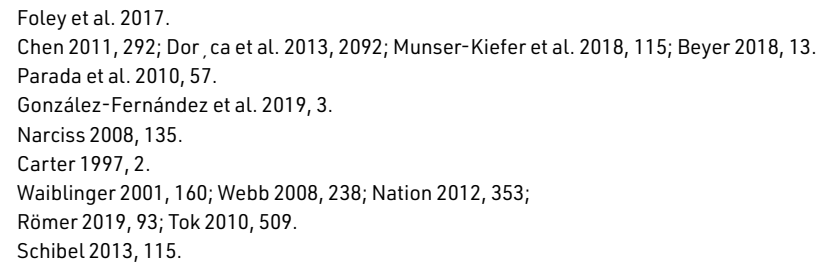




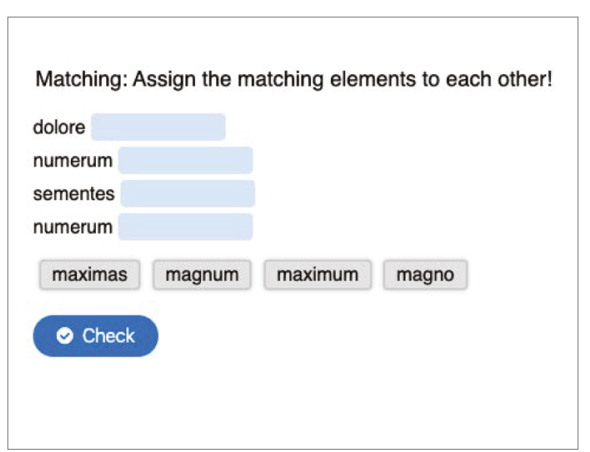

Fig. 2: Matching exercise for nouns with adjectival modifiers, created using H5P (Joubel 2018).
Cloze: Assign the words from the pool to the correct gaps!

Ita sive casu sive consilio deorum immortalium quae pars civitatis Helvetiae insignem calamitatem populo Romano intulerat ea princeps poenam persolvit. Qua in re Caesar non solum publicas etiam privatas iniurias ultus est quod eius soceri Lucli Pisonis avum Lucium Pisonem legatum Tigurini eodem proelio quo Cassium interfecerant. Hoc proelio facto reliquas copias Helvetiorum ut consequi posset pontem in Arari faciendum curat ita exercitum traducit. Helvetii repentino eius adventu commoti cum id quod ipsi diebus viginti aegerrime confecerant ut flumen transirent illum uno die fecisse intellegerent legatos ad eum mittunt. cuius legationis Divico princeps fuit qui bello Cassiano dux Helvetiorum fuerat. Is ita cum Caesare egit. pacem populus Romanus cum Helvetis faceret in eam partem ituros ibi futuros Helvetios ubi eos Caesar constituisset esse voluisset.

atque si atque sed atque

O Check

adjectival modifiers (see Fig. 2). Other setups may turn out to be even more effective, for example 'keyword in context' views, ${ }^{19}$ or cloze tests as a means of differentiating between similar conjunctions (see Fig. 3).

Using authentic language as a basis for the exercises has the added benefit of implicitly confronting learners with many linguistic patterns and structures, for example in syntax or lexis. This way, even if the focus of the exercise is on a very specific phenomenon, learners will also internalise many other properties of the target language that are not emphasised separately. ${ }^{20}$ Besides, using an interactive digital system to communicate such materials can be more inclusive, more motivating, and conducive to a deeper understanding of word meaning. ${ }^{21}$ Furthermore, automatic evaluation of exercises enables us to provide ongoing formative, visualized feedback, and to construct individual learning paths for each person. ${ }^{22}$ This may well be one of the most important benefits of NLP for language teaching.

\section{Treebanks and learners' expectations}

When learners acquire vocabulary, they do not just learn about the lexis, i.e. when to use which word. They also need to grasp the word's meaning and position in various contexts. In this view, the theoretical distinction between lexicon, syntax and semantics becomes blurred, or at least highly interwoven. ${ }^{23}$ Considering that there cannot be a full understanding of any word in a specific context without knowledge of its syntactic

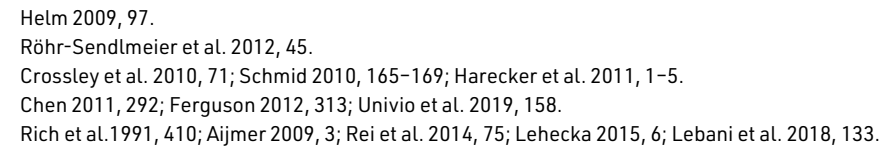


function, ${ }^{24}$ we need to make sure that advanced learners' expectations, when reading the beginning of a sentence, have been shaped and trained by as many similar contexts as possible. For beginners, on the other hand, the text passages that they are confronted with have to be chosen in a way that they do not match their expectations perfectly. In this manner, they will be forced to adapt their mental representation of syntagmatic structures in the target language, thus extending their knowledge. ${ }^{25}$

Historically, such experiential modifications of linguistic knowledge have been exemplified in grammar books, which often impose rather prescriptive standards and use several authentic instances of language use to support their claims, followed by a few exceptions where the general rule does not apply. ${ }^{26}$ With the advent of curated text corpora of decent size even for historical languages, however, we may now replace the textual basis from which we deduce linguistic assumptions with suitable ad hoc corpora. Treebanks, i.e. syntactically annotated text collections (often including multiple authors), should be used both as a standard reference for the target language in general and as a pool for extracting information about specific sub-corpora, for example all works from a certain author. If that author's works are to be read in school, teachers can access the relevant treebank ${ }^{27}$ through dedicated corpus search tools ${ }^{28}$ and see which constructions are particularly important to understand the chosen texts. Furthermore, educational publishing companies may choose to base their next textbook's vocabulary only on those texts that are part of the curriculum at later stages.

\section{Modelling the meaning of words}

While NLP practitioners have access to more and more lexical and syntactic resources to provide teachers with useful materials, the same cannot be readily said about semantics. There have been efforts to create expert databases ${ }^{29}$ that are supposed to represent human semantic knowledge. Unfortunately, these are often built from personal intuition rather than empirical evidence. One of the most promising approaches for overcoming this problem is distributional semantics, which defines a word's meaning by looking at its surrounding context. ${ }^{30}$ It has been on the rise in recent years, especially due the hype surrounding deep learning. ${ }^{31}$ Furthermore, good distributional semantic models (DSMs) do not just represent semantic relations, but also morphological or

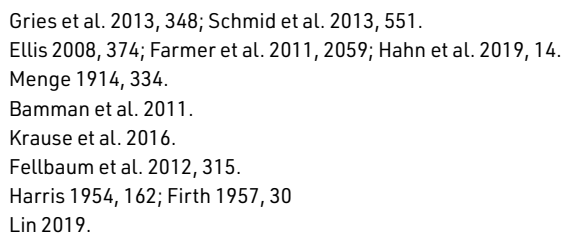


even pragmatic information ${ }^{32}$, which is not surprising given the interwovenness of the various linguistic levels that was mentioned above.

Obviously, such approaches suffer from many problems:

- They tend to ignore common knowledge that is available to every human but is never mentioned in the given texts. ${ }^{33}$

- They struggle to adequately represent rare or metaphoric word usage. ${ }^{34}$

- Their inferential power (for example by analogy) is very case-specific and cannot be easily generalised. ${ }^{35}$

- They often do not model polysemy at all and do not differentiate between, for example, synonymy and syntagmatic relatedness. ${ }^{36}$

Fortunately, these points have attracted attention and this has led to serious improvements, especially concerning the modelling of polysemy. ${ }^{37} \mathrm{~A}$ great deal of research has been done on using textual context as a source of information on a word's meaning, for example by hiding words in a text and making a machine fill the blanks correctly ${ }^{38}$ or by systematically comparing various computational operationalisations of linguistic knowledge. ${ }^{39}$ Thereby, standard procedures in philology, such as finding semantically related words for a given topic in a given text corpus, ${ }^{40}$ can be facilitated through machine learning output that is interactively visualized as a network (Fig. 4).

In such networks, users can start from a single word (veritas) and quickly expand on that word to find other related terms like simulatio (pretence), crederet (to trust) or suggerendis (to suggest). In this sense, the procedure is comparable to snowball sampling ${ }^{41}$ because once a user has found these additional terms, each one of them can be used as the basis for another search. Such search methods have been used with traditional linguistic resources as well (e.g. dictionaries, catalogues of synonyms etc.), but they have rarely been adapted to a specific researcher's target data. Using a dynamic machine learning approach enables NLP software to apply the general method (i.e. extracting word fields from a text) to almost any given corpus. The most important obstacle, then, will be to make the base architecture useful for as many cases as possible. This way, we can optimise the method for many different usage scenarios at the same time, instead of starting from scratch for every new text corpus.

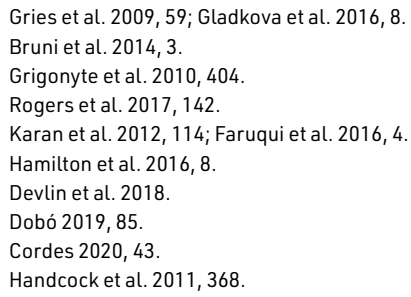




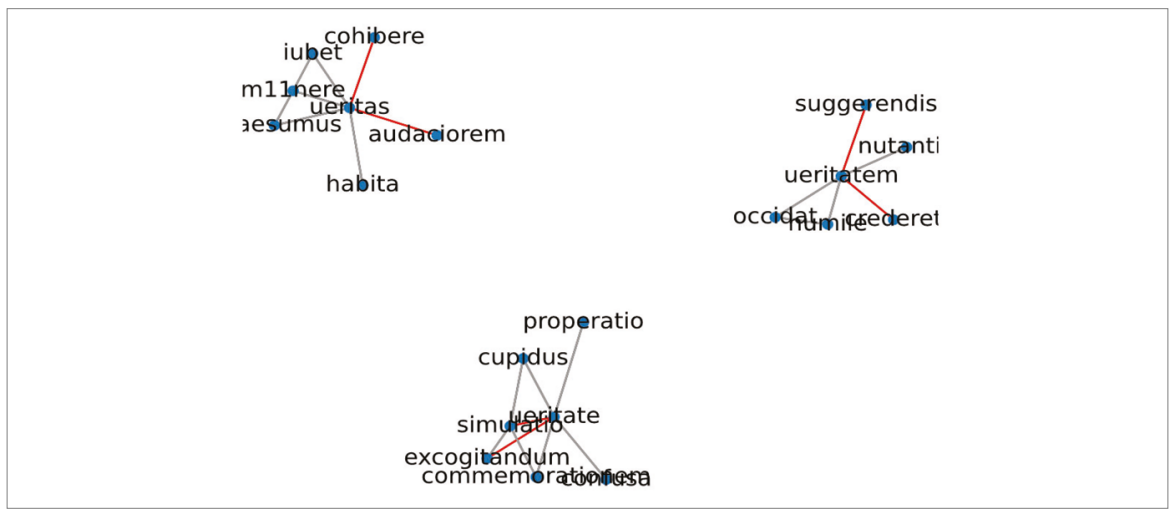

Fig. 4: Semantically related words for veritas in the Panegyrici Latini, a late antique text corpus. Relations are visualized as edges in a network, where particularly important ones are highlighted in red.

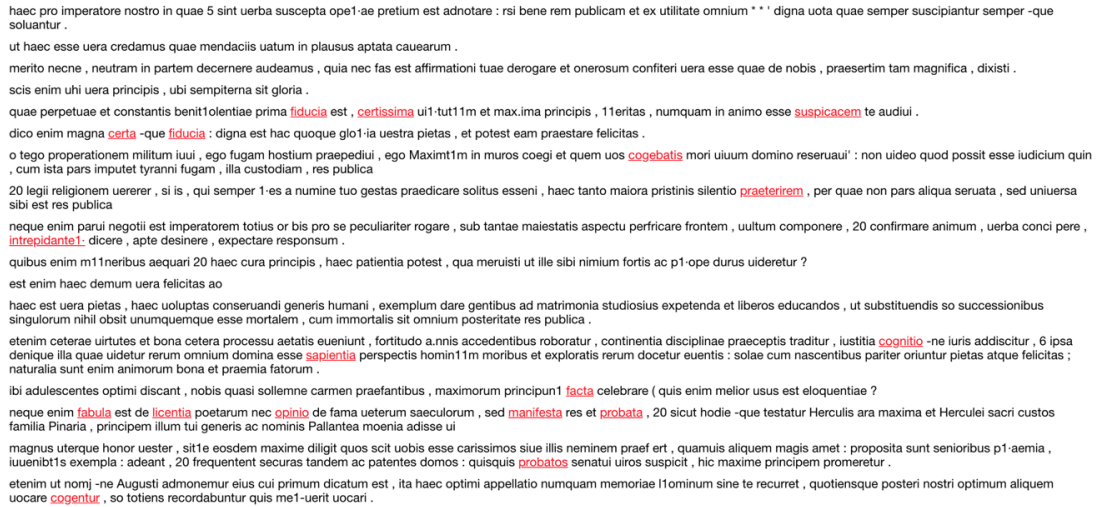

Fig. 5: Semantically related sentences for vera in the Panegyrici Latini, a late antique text corpus. Important words are highlighted in red. Note that many sentences do not contain the query word veritas, but are highly relevant, nevertheless.

Methodologically speaking, snowball sampling is applicable to entire sentences and documents as well (Fig. 5). Since the amount of linguistic output here is considerably larger, users will probably not interact with it in the same way as with the network. Instead, such lists can be seen as a semantic equivalent of 'keyword in context' views, i.e. depicting descriptions of the same target entity (here: factuality as designated by the input word vera) in various contexts. This is especially useful for teachers who do not want to convey the meaning of one specific term, but rather of an entire concept or topic, which in turn is often essential to a deep understanding of ancient texts. 
Another important aspect resides in the interpretability of NLP results..$^{42}$ Especially in the case of semantics, finding relevant responses to a given query often includes complex modelling, ${ }^{43}$ specific statistical measures ${ }^{44}$ or searching in additional resources. ${ }^{45}$ Usually, the ability of the underlying algorithms to explain results and the ability of those who applied the algorithm to explain why it produced those results, is less important for teachers than for researchers, but from an epistemological and educational perspective, there is much to be learned by applying introspection to the decision processes of artificial intelligence. This becomes apparent in cases where machines produce convincing visualizations using improper modelling. A good example is the stylometric study of Jeremi Ochab, ${ }^{46}$ in which a seemingly simple decision process (i.e. authorship attribution) is made more complicated by many confounding variables, such as text length or topic. ${ }^{47}$

\section{Conclusion}

In the end, teachers have to be aware that NLP can solve some problems better than others. It is quite suitable for training learners' vocabulary or even syntactic expectations by confronting them with interactive, individualized exercises and materials that have been tailored to their current state of knowledge. However, a teacher cannot rely solely on software because human domain-specific expertise and social sensitivity are needed to provide elaborate advanced feedback to the students. Moreover, machines may retrieve and visualize relevant search results very efficiently, but they must not take interpretation and decision-making out of the learners' hands because those processes constitute the core of consensus negotiation, and thus knowledge acquisition.

Besides, even in the easy cases, we must always be aware of risks such as systematic bias, weak statistical measures or overly suggestive visualizations. Apart from such implicit or hidden weaknesses, some tasks are known to be too difficult for contemporary machines, for example reliable and highly accurate parsing of syntax for historical languages. Fortunately, surpassing contemporary abilities is, in this case, arguably a question of a few years rather than decades. Other more complex tasks such as word sense disambiguation may need considerably more time to meet a similar milestone.

\footnotetext{
Doran et al. 2017, 4.

Divjak et al. 2009, 274; Weale et al. 2009, 29.

Hagiwara et al. 2009, 566.

Ono et al. 2015, 984-988.

Ochab et al. 2019.

Golcher et al. 2011, 31-33; Ochab et al. 2019, 141.
} 


\section{Author}

Konstantin Schulz, Humboldt-Universität zu Berlin, Institut für deutsche Sprache und Linguistik / Computer- und Medienservice

Konstantin Schulz studied Latin, History and ancient Greek in Potsdam and Berlin. He is currently researching digital methods of vocabulary acquisition in Latin language teaching in the DFG project CALLIDUS. His dissertation topic is semantic analysis of Latin texts using machine learning.

schulzkx@hu-berlin.de

\section{Useful resources}

- interactive exercises: $\mathrm{H} 5 \mathrm{P}$

- Latin vocabulary exercises: MachinaCallida

- visualization for linguistic annotations: CONLLU Viewer

- annotated ancient texts: AGLDT \& PROIEL

- corpus search and visualization: ANNIS

\section{References}

Aijmer, Karin (ed.) 2009. Corpora and Language Teaching, Amsterdam.

Bamman, David / Crane, Gregory 2011. The Ancient Greek and Latin Dependency Treebanks [AGLDT], Language Technology for Cultural Heritage, 79-98.

Beyer, Andrea 2018. Das Lateinlehrbuch aus Fachdidaktischer Perspektive: Theorie -Analyse-Konzeption, Heidelberg.

Bruni, Elia / Tran, Nam Khanh / Baroni, Marco 2014. Multimodal Distributional Semantics, Journal of. Artificial Intelligence Reearch (JAIR) 49, 1-47.

Carter, Terri G. M. 1997. Latin Vocabulary Acquisition: An Experiment Using Information-processing Techniques of Chunking and Imagery (Dissertation, University of North Texas). <https://digital.library.unt.edu/ark:/67531/ metadc277583/m1/11/> (last accessed May 27, 2021)

Chen, Ling-Hsiu 2011. Enhancement of Student Learning Performance Using Personalized Diagnosis and Remedial Learning System, Computers \& Education 56.1, 289-299.

Cordes, L. 2020. Wenn Fiktionen Fakten schaffen. Faktuales und fiktionales Erz"ahlen in den sp"atantiken Panegyrici Latini, in: Dustin Breitenwischer, Hanna-Myriam Häger and Julian Menninger (eds), Faktuales und fiktionales Erz"ahlen II. Geschichte-Medien-Praktiken, Würzburg, 31-56.

Crocker, Matthew W. 2013. Computational Psycholinguistics, in: Alexander Clark and Chris Fox and Shalom Lappin (eds), The Handbook of Computational Linguistics and Natural Language Processing, New Jersey, 482-514.

Crossley, Scott A. / Salsbury, Tom / McNamara, Danielle S. 2010. The Development of Semantic Relations in Second Language Speakers: A Case for Latent Semantic Analysis, Vigo International Journal of Applied Linguistics 7, 55-74.

Dale, Robert 2010. Classical Approaches to Natural Language Processing, in: Nitin Indurkhya and Fred J. Damera (eds) Handbook of Natural Language Processing, Boca Raton, 3-7.

Devlin, Jacob / Chang, Ming-Wei / Lee, Kenton /Toutanova, Kristina 2019. BERT: Pre-training of Deep Bidirectional Transformers for Language Understanding. Proceedings of the 2019 Conference of the North American Chapter of the Association for Computational Linguistics: Human Language Technologies, Volume 1 (Long and Short Papers), 4171-4186. <https://doi.org/10.18653/v1/N19-1423>

Divjak, Dagmar / Gries, Stefan T. 2009. Corpus-Based Cognitive Semantics: A Contrastive Study of Phasal Verbs in English and Russian, in: Barbara Lewandowska-Tomaszczyk / Katarzyna Dziwirek, Studies in cognitive corpus linguistics, 273-296. 
Dob 'o András 2019. A Comprehensive Analysis of the Parameters in the Creation and Comparison of Feature Vectors in Distributional Semantic Models for Multiple Languages (unpublished doctoral thesis, University of Szeged).

Doran, Derek / Schulz, Sarah / Besold, Tarek R. 2018. What Does Explainable Al Really Mean? A New Conceptualization of Perspectives, in Tarek R. Besold \& Oliver Kutz (eds), Proceedings of the First International Workshop on Comprehensibility and Explanation in Al and ML 2017 co-located with 16th International Conference of the Italian Association for Artificial Intelligence (AI*|A 2017), pp. 1-8. <http://ceur-ws.org/Vol-2071/CExAllA_2017_ paper_2.pdf> (last accessed May 27, 2021)

Dor, ca, Fabiao A. / Lima, Luciano V. / Fernandes, Márcia A. / Lopes Carlos R. 2013. Comparing Strategies for Modeling Students Learning Styles through Reinforcement Learning in Adaptive and Intelligent Educational Systems: An Experimental Analysis, Expert Systems with Applications 40.6, 2092-2101.

Ellis, Nick C. 2008. Usage-based and form-focused language acquisition: The associative learning of constructions, learned attention, and the limited L2 endstate, in: Peter Robinson / Nick C. Ellis (eds), Handbook of cognitive linguistics and second language acquisition, New York, 372-405.

Farmer, Thomas A. / Fine, Alex B. / Jaeger, Florian 2011. Implicit Context-Specific Learning Leads to Rapid Shifts in Syntactic Expectations, Proceedings of the Cognitive Science Society. Vol. 33, 2055-2060.

Faruqui, Manaal / Tsvetkov, Yulia / Rastogi, Pushpendre / Dyer, Chris 2016. Problems with Evaluation of Word Embeddings Using Word Similarity Tasks, in: arXiv preprintarXiv:1605.02276, 30-35.

Fellbaum, Christiane / Vossen, Piek 2012. Challenges for a Multilingual Wordnet, Language Resources and Evaluation 46.2, 313-326.

Ferguson, Rebecca 2012. Learning Analytics: Drivers, Developments and Challenges, International Journal of Technology Enhanced Learning 4.5/6, 304-317.

Firth, John R. 1957. A Synopsis of Linguistic Theory 1930-55, in: John R. Firth (ed.), Studies in Linguistic Analysis, Oxford, 1-32.

Foley, Joseph / Thompson, Linda 2017. Language Learning: A Lifelong Process, Abingdon.

Freie und Hansestadt Hamburg, Behörde für Bildung und Sport 2004. Rahmenplan Alte Sprachen: Latein, Griechisch. Bildungsplan Achtstufiges Gymnasium Sekundarstufe I. <http://epub.sub.uni-hamburg.de/epub/volltexte/2008/600/pdf/LATGRIE_Gy8.pdf> (last accessed May 27, 2021)

Gladkova, Anna / Drozd, Aleksandr / Matsuoka, Satoshi 2016. Analogy-Based Detection of Morphological and Semantic Relations with Word Embeddings: What Works and What Doesn't, in: Proceedings of the NAACL Student Research Workshop, 8-15.

Golcher, Felix / Reznicek, Mark 2011. Stylometry and the Interplay of Topic and L1 in the Different Annotation Layers in the FALKO Corpus, in: Anke Zeldes / Amir Lüdeling (eds), Proceedings of Quantitative Investigations in Theoretical Linguistics 4, Berlin, 29-34.

Gonz'alez-Fern'andez, Beatriz / Schmitt, Norbert 2019. Word Knowledge: Exploring the Relationships and Order of Acquisition of Vocabulary Knowledge Components, Sheffield.

Gries, Stefan T. / Wulff, Stefanie 2013. The Genitive Alternation in Chinese and German ESL Learners: Towardsa Multifactorial Notion of Context in Learner Corpus Research, International Journal of Corpus Linguistics 18.3, 327-356.

Gries, Stefan T. / Divjak, Dagmar 2009. Behavioral Profiles: A Corpus-Based Approach to Cognitive Semantic Analysis, New directions in cognitive linguistics, 57-75.

Grigonyte ', Gintaré / Cordeiro, João / Dias, Gaël / Moraliyski, Rumen / Brazdil, Pavel 2010. Paraphrase Alignment for Synonym Evidence Discovery, in: Chu-Ren Huang and Dan Jurafsky (eds), Proceedings of the 23rd International Conference on Computational Linguistics, Beijing, 403-411.

Hagiwara, Masato / Ogawa, Yasuhiro / Toyama, Katsuhiko 2009. Supervised Synonym Acquisition Using Distributional Features and Syntactic Patterns, Information and Media Technologies 4.2, 558-582.

Hahn, Michael / Baroni, Marco 2019. Tabula Nearly Rasa: Probing the Linguistic Knowledge of Character-Level Neural Language Models Trained on Unsegmented Text, arXiv preprint arXiv:1906.07285, 1-19.

Hamilton, William L. / Leskovec, Jure / Jurafsky, Dan 2016. Diachronic Word Embeddings Reveal Statistical Laws of Semantic Change, arXiv preprintarXiv:1605.09096, 1489-1501.

Handcock, Mark S. / Gile, Krista J. 2011. Comment: On the Concept of Snowball Sampling, Sociological Methodology 41.1, 367-371. 
Harecker, Gabriele / Lehner-Wieternik, Angela 2011. Computer-Based Language Learning with Interactive Web Exercises, ICT for Language Learning, 1-5.

Harris, Zellig S. 1954. Distributional Structure, Word 10.2-3, 146-162.

Helm, Francesca 2009. Language and Culture in an Online Context: What Can Learner Diaries Tell Us about Intercultural Competence?, Language and Intercultural Communication 9.2, 91-104.

Jones, Randall L. / Tschirner, Erwin 2006. A Frequency Dictionary of German: Core Vocabulary for Learners, Abingdon.

Joubel, A. (2018). H5P. Create, share and reuse interactive HTML5 content in your browser (1.3.3 (Standalone)) [Web Application]. Joubel AS. <https://h5p.org/about-the-project> (last accessed May 27, 2021)

Karakanta, Alina / Dehdari, Jon / Genabith, Josef van 2018. Neural Machine Translation for Low-Resource Languages without Parallel Corpora, Machine Translation 32, 167-189.

Karan, Mladen / Šnajder, Jan / Bašić, Bojana D. 2012. Distributional Semantics Approach to Detecting Synonyms in Croatian Language, Information Society, 111-116.

Krause, Thomas 2016. graph ANNIS: A Fast Query Engine for Deeply Annotated Linguistic Corpora, Journal for Language Technology and Computational Linguistics 31.1,1-25.

Lebani, Gianluca E. / Lenci, Alessandro 2018. A Distributional Model of Verb-Specific Semantic Roles Inferences, Language, Cognition, and Computational Models, 118.

Lehecka, Tomas 2015. Collocation and colligation, in Jef Verschueren / Jan-Ola Östman / Jan Blommaert / Chris Bulcaen (eds), Handbook of pragmatics online, Amsterdam, 1-23. <https://doi.org/10.1075/hop.19.col2>.

Lin, Jimmy 2019. The Neural Hype, Justified! A Recantation, ACM Special Interest Group on Information Retrieval Forum. Vol. 53, 88-93.

Ljunglöf, Peter / Wirén, Mats 2010. Syntactic Parsing, in: Nitin Indurkhya and Fred J. Damerau, Handbook of Natural Language Processing, London, 59-92.McGillivray, Barbara 2013. Methods in Latin Computational Linguistics, Leiden, Boston. <https://books.google.de/books?hl=de\&lr=\&id=33dfAgAAQBAJ> (last accessed January 5, 2021)

Menge, Hermann 1914. Repetitorium der lateinischen Syntax und Stilistik: Ein Lernbuch für Studierende und vorgeschrittene Schüler, zugleich ein praktisches Repertorium für Lehrer, Wolfenbüttel.

Munser-Kiefer, Meike / Martschinke, Sabine / Hartinger, Andreas 2018. Subjektive Arbeitsbelastung von Lehrkräften in jahrgangsgemischten dritten und vierten Klassen, in: Susanne Miller, Birgit Holler-Nowitzki, Brigitte Kottmann, Svenja Lesemann, Birte Letmathe-Henkel, Nikolaus Meyer, René Schröder and Katrin Velten, Profession und Disziplin: Grundschulpädagogik im Diskurs, Wiesbaden,114-120.

Narciss, Susanne 2008. Feedback Strategies for Interactive Learning Tasks, in: J. Michael Spector / M. David Merrill / Jeroen van Merrienboer / Marcy P. Driscoll (eds), Handbook of Research on Educational Communications and Technology. 3rd edition, New York, 125-144.

Nation, lan Stephen Paul 2012. Learning Vocabulary in Another Language, 14th edition, Cambridge.

Ochab, Jeremi K. / Essler, Holger 2019. Stylometry of Literary Papyri, Proceedings of the 3rd International Conference on Digital Access to Textual Cultural Heritage, 139-142.

Ono, Masataka / Miwa Makoto / Sasaki, Yutaka 2015. Word Embedding-Based Antonym Detection Using Thesauri and Distributional Information, Proceedings of the 2015 Conference of the North American Chapter of the Association for Computational Linguistics: Human Language Technologies, 984-989.

Palmer, David D. 2010. Text Preprocessing, in: Nitin Indurkhya and Fred J. Damerau, Handbook of Natural Language Processing, London, 9-30.

Parada, Carolina / Sethy, Abhinav / Dredze, Mark / Jelinek, Frederick 2010. A Spoken Term Detection Framework for Recovering Out-of-Vocabulary Words Using the Web, 11th Annual Conference of the International Speech Communication Association 2010 (INTERSPEECH2010), Vol.2, 1269-1272.

Ragni, Anton / Katherine Mary Knill / Shakti P. Rath / Mark John Gales 2015. Data Augmentation for Low Resource Languages, in: Haizhou Li / Helen M. Meng / Bin Ma / Engsiong Chng / Lei Xie (eds), 15th Annual Conference of the International Speech Communication Association (INTERSPEECH 2014), New York, 810-814.

Rei, Marek / Briscoe, Ted 2014. Looking for Hyponyms in Vector Space, Proceedings of the Eighteenth Conference on Computational Natural Language Learning, 68-77.

Rich, Elaine / Knight, Kevin 1991. Artificial Intelligence, New York. 
Robillard, Manon / Mayer-Crittenden, Chantal / Minor-Corriveau, Michèle / Bélanger, Roxanne 2014. Monolingual and Bilingual Children with and without Primary Language Impairment: Core Vocabulary Comparison, Augmentative and alternative communication 30.3, 267-278.

Rogers, Anna / Drozd, Aleksandr / Li, Bofang 2017. The (Too Many) Problems of Analogical Reasoning with Word Vectors, Proceedings of the 6th Joint Conference on Lexical and Computational Semantics (*SEM2017), 135148.

Röhr-Sendlmeier, Una M. / Käser Udo 2012. Das Lernen Komplexer Sprachlicher Strukturen -Wissenserwerb Nach Unterschiedlichen Lernmodi, in: Una M. Röhr-Sendlmeier, Inzidentelles Lernen-wie wir beiläufig Wissen erwerben, Berlin, 43-85.

Römer, Ute 2009. Corpus Research and Practice, in: Aijmer, Karin (ed.) 2009. Corpora and Language Teaching, Amsterdam, 83-98.

Schibel, Wolfgang 2013. Zur Aneignung Lateinischer Literatur und Sprache, Forum Classicum, 113-124.

Schmid, Euline C. 2010. Developing Competencies for Using the Interactive Whiteboard to Implement Communicative Language Teaching in the English as a Foreign Language Classroom, Technology, Pedagogy and Education 19.2, 159-172.

Schmid, Hans-Jörg / Küchenhoff, Helmut 2013. Collostructional Analysis and Other Ways of Measuring Lexicogrammatical Attraction: Theoretical Premises. Practical Problems and Cognitive Underpinnings, Cognitive Linguistics 24.3, 531-577.

Textor, Mark 2011. Frege on Sense and Reference, in: Klaus von Heusinger, Claudie Maienborn and Paul Portner (eds), Semantics: An International Handbook of Natural Language Meaning, Berlin, 25-49.

Tok, Hidayet 2010. TEFL Textbook Evaluation: From Teachers' Perspectives, Educational Research and Reviews 5.9, 508-517.

Univio, Diana Jazmin / Andrea del Pilar Pérez 2019. Ipsative Assessment of Essay Writing to Foster Reflection and Self-Awareness of Progress, in: Eddy White / Thomas Delaney (eds), Handbook of Research on Assessment Literacy and Teacher-Made Testing in the Language Classroom, Hershey/PA, 157-180. <https://www.igi-global.com/chapter/ipsative-assessment-of-essay-writing-to-foster-reflection-and-self-awareness-of-progress/217152> (last accessed May 27, 2021)

Utz, Clement 2000. Mutter Latein und unsere Schüler - Überlegungen zu Umfang und Aufbau des Wortschatzes [BWS], in: Peter Neukam (ed.), Antike Literatur - Mensch, Sprache, Welt. Dialog Schule und Wissenschaft, München, 146-172.

Waiblinger, Franz P. 2001. Vorschläge zu einem neuen Konzept des Sprachunterrichts auf der Grundlage psycholinguistischer Erkenntnisse, Forum Classicum 3, 160-167.

Weale, Timothy / Brew, Chris / Fosler-Lussier, Eric 2009. Using the Wiktionary Graph Structure for Synonym Detection, Proceedings of the 2009 Workshop on The People's Web Meets NLP: Collaboratively Constructed Semantic Resources. Suntec, Singapore: Association for Computational Linguistics, 28-31.

Webb, Stuart 2008. The Effects of Context on Incidental Vocabulary Learning, Reading in a Foreign Language 20.2, 232-245. 